BULLETIN Bulletin hispanique

HISPANIQUE Université Michel de Montaigne Bordeaux

120-1 | 2018

Varia

\title{
Aurélia Moyà-Freire, Ma vie en France. Cahier d'exil d'une adolescente espagnole (1939-1943)
}

Toulouse, Presses universitaires du Midi, 2017

Jacques Issorel

\section{CpenEdition}

Journals

Édition électronique

URL : https://journals.openedition.org/bulletinhispanique/6327

DOI : 10.4000/bulletinhispanique.6327

ISSN : $1775-3821$

\section{Éditeur}

Presses universitaires de Bordeaux

Édition imprimée

Date de publication : 30 juin 2018

Pagination : 373-375

ISBN : 979-10-300-0298-0

ISSN : 0007-4640

Référence électronique

Jacques Issorel, « Aurélia Moyà-Freire, Ma vie en France. Cahier d'exil d'une adolescente espagnole (1939-1943) », Bulletin hispanique [En ligne], 120-1 | 2018, mis en ligne le 30 juin 2018, consulté le 07 janvier 2022. URL : http://journals.openedition.org/bulletinhispanique/6327 ; DOI : https://doi.org/ 10.4000/bulletinhispanique.6327

Ce document a été généré automatiquement le 7 janvier 2022

Tous droits réservés 


\section{Aurélia Moyà-Freire, Ma vie en France. Cahier d'exil d'une adolescente espagnole (1939-1943)}

Toulouse, Presses universitaires du Midi, 2017

Jacques Issorel

\section{RÉFÉRENCE}

Aurélia Moyà-Freire, Ma vie en France. Cahier d'exil d'une adolescente espagnole (1939-1943), avant-propos, appareil critique et postface de Rose DUROUX, Célia KEREN et Danielle CORRADO, Toulouse, Presses universitaires du Midi, 2017, 113 p. -(Hespérides).

1 Les trois éditrices du «cahier d'exil » d'Aurélia Moyà-Freire soulignent avec raison le caractère exceptionnel de ce document, retrouvé par hasard par sa fille Cinta dans un secrétaire de la maison familiale quelque quarante ans après avoir été écrit. Exceptionnel, car dans la longue série des témoignages d'exilés républicains espagnols on trouve essentiellement des textes écrits par des hommes et concernant les hommes internés dans les camps du Roussillon et d'ailleurs (Bram, Gurs, etc.). Peu retracent les épreuves que durent supporter, pendant de longs mois, les femmes - séparées de leurs maris ou de leurs compagnons - et leurs enfants, tantôt dans des villages, tantôt dans des centres d'hébergement. Les témoignages de femmes sont, dans la plupart des cas, l'œuvre de personnalités politiques (Federica Montseny, Victoria Kent) ou d'écrivaines comme Rosa Chacel. Aucun, en tout cas, n'a pour auteur une adolescente telle qu'Aurélia, qui vient d'avoir quatorze ans lorsqu'elle franchit avec douze femmes et enfants de sa famille la frontière au Perthus, le $1^{\text {er }}$ février 1939 " par une nuit obscure, lugubre» (p. 13).

2 Le groupe arrive à pied du lointain village d'Arbeca, près de Lérida, et va se retrouver, presque sans transition, à Plancher-Bas, un village de Haute-Saône. C'est là qu'Aurélia jette au brouillon quelques notes en vue de la rédaction de Ma vie en France, qu'elle 
commencera quand la famille, contrainte d'abandonner ce village où elle a été accueillie avec chaleur ("je suis touchée de reconnaissance jusqu'au fond du cœur", p.25), sera recluse dans le camp de concentration de Miellin, où elle demeurera pendant cinq mois. Il aurait été logique qu'Aurélia composât son récit dans sa langue maternelle, le catalan, ou en castillan. C'est pourtant en français qu'elle s'applique à rédiger afin de progresser dans notre langue, en mettant à profit ses souvenirs d'écolière et en s'aidant de son dictionnaire bilingue Niceto Alcalá-Zamora, glissé dans son maigre bagage en abandonnant la maison familiale. Ayant, malgré son jeune âge, l'intuition que le séjour en France se prolongera, elle s'efforce tout au long du périple imposé aux Moyà (dix lieux de résidence entre 1939 et 1943 !) d'aller à l'école chaque fois que cela lui est possible et réussit même à obtenir le certificat d'études primaires en 1942 .

3 Elle n'oublie pas pour autant son village, son pays, ceux qui y sont restés, vivent dans la misère, souffrent en prison ou meurent fusillés (« Nouvelles d'Espagne », p. 31-32). Lorsqu'elle évoque l'Espagne, le mot " amour » revient sous sa plume et « va de pair avec le "désir" de retour, lancinant, obsessionnel» (postface, p. 85). De même «le réseau sémantique est, immanquablement, celui de la douleur» (ibid., p. 84), quand la réalité de la situation s'impose à elle : elle est une exilée, une étrangère, arrachée à sa terre natale, à la " belle Espagne joyeuse d'autrefois» (p. 42). Prise en tenaille entre l'amour du pays perdu et la volonté d'intégration, Aurélia ne s'abandonne jamais au désespoir, mais apparaît, au fil des chapitres, comme "un être éminemment positif " (postface, p. 85) : « Je me demande parfois comment cela finira, écrit-elle, néanmoins ce sera sans nul doute à notre avantage, pour le moment notre moral est excellent puisque les circonstances s'unissent à nous pour nous donner un peu d'espoir pour ce qui s'appelle : le but de nos idées » (p. 65).

4 Le récit d'Aurélia, agrémenté de 154 notes sobres, précises, utiles, nous renseigne sur le difficile vécu d'une famille espagnole, ballotée sans explication d'un lieu à un autre, tantôt accueillie avec bonté par de "bonne[s] dame[s]», comme Mme Deruy, l'institutrice d'Aurélia, qui la traite « comme un membre de la famille» (p. 63), tantôt ignoblement exploitée et humiliée à Hérouvillette (Calvados) par un patron indigne. Le regard d'Aurélia se porte aussi au-delà du quotidien. Elle suit l'évolution des événements internationaux : l'entrée en guerre de la France, puis de l'Italie ( « un coup de poignard dans le dos de la France », p. 49), la mobilisation, l'armistice, la bataille de Stalingrad. Ainsi que cet aspect est finement analysé dans la postface, on lit entre les lignes le soutien que la jeune fille et les siens apportent aux résistants. Aurélia sait que sur ce point elle doit rester discrète dans son cahier que la gestapo pourrait saisir à tout moment.

5 Ce livre est deux fois précieux. D'une part, le texte d'Aurélia, lucide, sans cesse poignant, résolument optimiste malgré les épreuves et les espoirs déçus (le départ manqué vers le Mexique), est représentatif de ce que fut la vie quotidienne de dizaines de milliers de femmes et d'enfants espagnols dans la France des années 1939-1943. C'est un beau témoignage humain, il force l'admiration. D'autre part, les quelque quarante pages de l'avant-propos et de la postface, par leur finesse psychologique et les subtiles analyses textuelles qu'elles apportent, constituent un modèle de lecture pour un document tel que celui-ci. Ces pages exaltent la valeur historique et la beauté du Cahier de « Mémoires » d'Aurélia Moyà-Freire. 
6 Une bibliographie succincte et quinze illustrations (photos, facsimilés du cahier, etc.) complètent utilement ce livre agréablement présenté.

\section{AUTEURS}

JACQUES ISSOREL

Université de Perpignan 